\title{
Psikolojik Danışma ve Rehberlik Alanında Analog Araştırmalar
}

\author{
Barış YAKA*
}

\begin{abstract}
Öz
Analog araştırma kavramı esas olarak, doğal koşullara benzer koşullarda gerçekleştirilen deneysel araştırmayı ifade etmektedir. Analog araştırma yöntemi, psikolojik danışma araştırmaları kapsamında ilk kez kullanıldığı tarihten bugüne, alanda kabul gören ve özellikle bir dönem çok popüler hâle gelmiş, oldukça çeşitli ve yaratıcı biçimlerde kullanılan bir araştırma yöntemidir. Analog araştırmalar, özellikle deneysel kontrol ve etik konularında araştırmacılara çeşitli avantajlar sağlamaktadır. Bununla birlikte birçok araştırmacı, analog araştırmaların en belirgin ve önemli sınırlılığının dış geçerlilik olduğunu ifade etmektedir. Ancak, analog araştırmalarla ilgili tartı̧̧malar büyük ölçüde, deneysel psikolojik danışma araştırmalarının literatürde genellikle, analog araştırmalar ve doğal koşullarda gerçekleştirilen araştırmalar şeklinde ikiye ayrılarak kavramlaştırılmasından kaynaklanmaktadır. Analog araştırma yönteminin, Türkiye'de psikolojik danışma ve rehberlik alanında deneysel araştırma yöntemiyle ele alınması gereken meselelerde, araştırmacılara yardımcı olabilecek başta gelen yöntemlerden biri olduğu düşünülmektedir. Ayrıca, bu makalede biraz da olsa gerçekleştirilmeye çalışılan yöntem bilimsel tartışmanın, incelemenin, Türkiye'de daha fazla yapılması gerektiğine inanılmaktadır.
\end{abstract}

Anahtar kelimeler: psikolojik danışma araştırmaları, analog araştırma, deneysel araştırma, laboratuvar araştırmaları, dış geçerlilik.

\footnotetext{
*Yrd. Doç. Dr., Ege Üniversitesi Eğitim Fakültesi, baris.yaka@ege.edu.tr
} 


\title{
Analogue Research in Counseling and Guidance
}

\begin{abstract}
Essentially, an analogue research is an experimental research conducted under conditions that resemble natural conditions. Analogue research which has been accepted in the field and also has become very popular for a period is a kind of research that is used in quite various and creative ways since it has been used for the first time in counseling researches. Analogue research has different advantages for researchers especially on experimental control and ethical issues. However many researcher denote that the most significant and important limitation of analogue methodology is external validity. Discussions related to analogue research mainly arise from dichotomizing experimental counseling research as analogue or naturalistic research often in the literature. It is assumed that analogue research may be mainly helpful for researchers about issues needed to be examined by experimental research in counseling and guidance in Turkey. Moreover, it is thought that similar methodological discussions and examinations somewhat carried out in this article should be carried out in Turkey further.
\end{abstract}

Key words: counseling research, analogue research, experimental research, laboratory research, external validity. 

Psikolojik Danışma ve Rehberlik Alanında Analog Araştırmalar

Analog kelimesi, Türkçeye Fransızcadan (analogue) girmiştir ve benzer, eş anlamlarına gelmektedir ("Analog," tarihsiz). Yöntem bilimsel bir terim olarak Türkiye dışındaki psikoterapi/psikolojik danışma (ve rehberlik) ${ }^{1}$ araştırmaları literatüründe çokça geçmesine rağmen, Türkiye'deki literatürde hemen hiç geçmemektedir. Her ne kadar analog araştırma kapsamında betimsel araştırmalar da yer alıyor olsa da literatürde bunlardan nadiren bahsedilmektedir (Gelso, 1979). Psikolojik danışma araştırmalarında analog araştırma esas olarak, doğal koşullara benzer koşullarda gerçekleştirilen deneysel araştırmayı ifade etmektedir (Cook ve Rumrill, 2005; Cowen, 1961; Heller, 1971; Heppner, Wampold ve Kivlighan, 2008; Kazdin, 1978, 1991; Kiesler, 1971; Lazarus, 1963; Strong, 1971). Burada benzerlikten kastedilen; araştırma kapsamında psikolojik danışmanın, danışanın, psikolojik danışma sürecinin ve/veya psikolojik danışma sürecinin yürütüldüğgu ortamın, herhangi bir yönden tam olarak doğal psikolojik danısma koşullarındaki gibi olmamasıdır (ör. gerçek psikolojik danışmanlar yerine psikolojik danışman adaylarının kullanılması; gerçek danışanlar yerine standart danışanların kullanılması; psikolojik danışma oturumlarının 30-60 dakika yerine yaklaşık 1015 dakika ile sınırlı tutulması; psikolojik danışma sürecinin bir psikolojik danışma merkezi/klinik yerine bir laboratuvarda yürütülmesi). Bu nedenle analog araştırmalar literatürde sıklıkla, laboratuvar araştırmaları olarak ele alınırlar (ör. Cowen, 1961; Gelso, 1979; Heppner ve dĭ̆., 2008; Strong, 1971). Ayrica Keet (1948) ve Goldstein, Heller ve Sechrest (1966) de analog araştırmaları minyatür psikolojik danışma olarak tanımlamışlardır.

Psikolojik danışma araştırmaları kapsamında ilk analog araştırmanın, Keet tarafından 1948'de gerçekleştirildiği kabul edilmektedir (Bordin, 1965; Kushner, 1978). Ancak analog araştırmaların, psikolojik danışma araştırmalarında Türkiye dışında, özellikle 1960'ların sonlarından 1980'lerin başlarına kadar çokça gerçekleştirildiği görülmektedir. Bununla birlikte, dünyada danışma psikolojisi/psikolojik danışma alanının sancak gemisi konumunda olan iki dergi, The Counseling Psychologist ve Journal of Counseling Psychology'de (JCP) 1979-2008 yılları arasında yayımlanan makaleleri inceleyen Scheel ve diğ. (2011a), her iki dergide de analog araştırmaların sayısının söz konusu yıllar boyunca keskin bir biçimde düştügünü belirtmiştir. Scheel ve diğ., analog araştırmaların sayısındaki bu düşüşün, psikolojik danışma süreç ve sonucunu daha iyi anlamamız açısından olumlu olmayacağını ileri sürmüştür.

1 Her ne kadar psikoterapi ile psikolojik danışma (ve rehberlik) arasında tarihsel ve bağlamsal bazı farklılıklar olsa da ortak noktalarının çok daha fazla olması nedeniyle makalede terim olarak sadece biri, psikolojik danışma kullanılmıştır. 
Erford ve diğ. (2011) de gene dünyada psikolojik danışma alanının önemli dergileri arasinda yer alan Journal of Counseling \& Development'ta 1994-2009 yılları arasında yayımlanan makaleleri incelemiş ve araştırmaların sadece yaklaşık \%11'inin deneysel araştırmalardan (gerçek deneysel araştırma, yarı deneysel araştırma, tek gruplu araştırma ve tek denekli araştırma) oluştuğunu bildirmiştir. Bu bulguyla ilgili olarak Erford ve diğ., bu tür araştırmalara ait makalelerin sayısının artmasının, etkili psikolojik danışma müdahalelerine ilişkin bilgi birikiminin devamı için son derece önemli olduğunu ifade etmiştir.

Bunların dışında Türkiye'de de psikolojik danışma alanında (ör. psikolojik danışman eğitiminde, psikolojik sorunların çözümünde) ihtiyaç duyulan çeşitli müdahale yöntemlerinin geliştirilmesine, uygulanmasına ve etkisinin kalıcılığına ilişkin araştırmaların yeterli sayıda olmadığı gözlemlenmektedir. Bu gözlemi; Güven, Kısaç, Ercan ve Yalçın'ın (2009) bulguları da desteklemektedir. Güven ve diğ. (2009) tarafından, psikolojik danışma alanında Türkiye'deki en önemli dergi olan Türk Psikolojik Danışma ve Rehberlik Dergisi'nde 1990-2008 yılları arasında yayımlanan makaleler incelenmiş ve bunların, araştırma türü açısından sadece \%7.07'sinin deneysel araştırmalara ait olduğu görülmüştür. Buna göre Güven ve diğ., Türkiye'de psikolojik danışma alanında, etkililiğin değerlendirildiği araştırmaların sayısının artırılması gerektiğini belirtmiştir.

Özetle deneysel araştırma yöntemleri, psikolojik danışmanların etkili psikolojik danışma hizmetleri geliştirmelerinde kullanabilecekleri değerli araçlardır (Strong, 1971). İyi bir deneysel araştırma, neden-sonuç ilişkilerinin anlaşılmasına olanak sağlar (Harmon, 1978). Scheel ve diğ. (2011b) de psikolojik danışma alanında analog araştırmaların; yeni müdahale yöntemlerinin geliştirilmesi, kuramsal meselelerin derinlemesine incelenmesi ve önemli, yeni bağımlı değişkenlerin keşfedilmesi konularında özellikle gerekli olduğunu belirtmiştir. Sonuç olarak bu makalenin amaçları; Türkiye'deki psikolojik danışma araştırmaları literatüründe hemen hiç geçmeyen analog araştırma kavramını genel hatlarıyla tanıtmak, analog araştırmaların önemine dikkati çekmek ve analog araştırma yöntemiyle ilgili literatürde yer alan başlıca görüşleri sunmaktır.

\section{Analog Araştırmaların Türleri}

Analog araştırma yöntemi, psikolojik danışma araştırmaları kapsamında ilk kez kullanıldığı tarihten bugüne; Kushner'ın (1978) ifadesiyle, alanda kabul gören ve özellikle bir dönem çok popüler hâle gelen bir araştırma yöntemi olmuştur. Analog araştırma yöntemi bütün bu yıllar boyunca araştırmacılar tarafından; canlı psikolojik danışma sürecine yer verilmeyen son derece yapay koşullar ile canlı psikolojik danışma sürecine yer verilen son derece doğal koşullar arasında 
değişen bir yelpazede, oldukça çeşitli ve yaratıı biçimlerde kullanılmıştır (Kushner, 1978). Esasen literatürde, üzerinde fikir birliği oluşmuş belirli analog araştırma türlerinin varlığından söz etmek pek mümkün değildir. Bununla birlikte örneğin Munley (1974), JCP'de yayımlanan analog araştırmaları beş ana kategoriye ayırmıştır: (a) Görsel-işitsel çalışmalar-psikolojik danışman davranışı bağımlı değişken, (b) görsel-işitsel çalışmalar-danışan davranışı bağımlı değişken, (c) yarı-psikolojik danışma görüşmeleri-danışan davranışı bağımlı değişken, (d) yarı-psikolojik danışma görüşmeleri-psikolojik danışman davranışı bağımlı değişken ve (e) psikolojik danışmaya benzemeyen deneysel görevler. Munley'nin ortaya koyduğu söz konusu analog araştırma kategorileri, Kushner'ın (1978) vurguladığı gibi analog araştırma yönteminin ne kadar çeşitli ve yaratıcı biçimlerde kullanılmış olduğunu göstermesi açısından önemli bir örnektir.

Munley'nin (1974) ortaya koyduğu birinci kategorideki çalışmalarda (a) bir psikolojik danışmana veya psikolojik danışman grubuna uyaran olarak, bir danışana ait ses kaydı veya film sunulur; (b) psikolojik danışman deneklerden, kendilerini söz konusu ses kaydı veya filmdeki danışanın psikolojik danışmanı olarak düşünmeleri ve (c) danışanın sözel ve/veya sözsüz ifadelerine karşılık bazı tepkiler vermeleri istenir. Bu çalışmalarda, danışan davranış veya özellikleri ve/veya psikolojik danışman özellikleri bağımsız değişkenler olarak ele alınır ve psikolojik danışman davranışlarına etkileri incelenir (Munley, 1974). İkinci kategorideki çalışmalar birinci kategorideki çalışmalar gibidir; ancak bu kez, danışan deneklere uyaran olarak bir psikolojik danışmana ait ses kaydı veya film sunulur (Munley, 1974). Üçüncü kategorideki çalışmalarda; psikolojik danışman davranış veya özelliklerinin danışan davranışlarına etkisini değerlendirmek amacıyla bir psikolojik danışmanın, önceden belirlenen davranışları sistematik olarak farklı biçimlerde sergilediği bir psikolojik danışma görüşmesi simülasyonu düzenlenir (Munley, 1974). Dördüncü kategorideki çalışmalar da üçüncü kategorideki çalışmalar gibidir; ancak bu kez genellikle, psikolojik danışman deneklerin gerçek danışanlarla karşı karşıya olduklarına inandıkları psikolojik danışma türü bir görüşme düzenlenir ve daha önce eğitilmiş olan danışan konumundaki kişiler, çeşitli değişkenlerde manipülasyon yapmak amacıyla önceden belirlenen davranışları sergiler (Munley, 1974). Munley'nin belirlediği son kategoride yer alan çalışmalarda ise denekler genellikle başlıca deneysel görev olarak, araştırmacıyla iş birliği içinde olan kişilerle bir müzakereye katılır ve belirli bir konuyu (ör. kürtaj) tartışırlar. Müzakere süreci boyunca, araştırmacıyla iş birliği içinde olan kişiler sistematik olarak farklı davranış ve tutumlar sergiler ve sonra, bunların sonuca etkisi değerlendirilir (Munley, 1974). 
Analog Araştırmaların Avantaj ve Dezavantajları

Bilindiği gibi psikolojik danışma, olağanüstü karmaşık bir süreçtir; danışanlar çeşitlidir, psikolojik danışmanlar çeşitlidir ve son derece etkileşimli, duygu yüklü bir iletişim sürecidir (Heppner ve diğ., 2008). Bu durumda analog araştırma yönteminin öne çıkan kullanılma nedenleri ve avantajları şu dört noktada toplanmaktadır: (a) Doğal psikolojik danışma koşullarında deneysel araştırma gerçekleştirmek çeşitli pratik nedenlerle genellikle mümkün değildir (Cook ve Rumrill, 2005; Heller, 1971; Heppner ve diğ., 2008; Kazdin, 1978, 1991); (b) ayrıca bu koşullarda deneysel araştırma gerçekleştirmeyi sınırlayan birtakım etik engeller bulunmaktadır (Cook ve Rumrill, 2005; Gelso, 1979; Heppner ve diğ., 2008; Kazdin, 1991; Kushner, 1978; Scheel ve diğ., 2011a; Weidmann, Conradi, Gröger, Fehm ve Fydrich, 2009); (c) analog araştırmalar; deneysel kontrolü, dolayısıyla iç geçerliliği son derece artırmaktadır (Borkovec ve Rachman, 1979; Cook ve Rumrill, 2005; Cowen, 1961; Gelso, 1979; Heppner ve diğ., 2008; Kazdin, 1978; Kushner, 1978; Scheel ve diğ., 2011a; Zane, Hall, Sue, Young ve Nunez, 2004) ve (d) çok spesifik meseleleri bile inceleyip açılama olanağı sağlamaktadır (Borkovec ve Rachman, 1979; Cowen, 1961; Gelso, 1979; Heppner ve diğ., 2008; Kazdin, 1978; Zane ve diğ., 2004).

Doğal psikolojik danışma koşullarında deneysel araştırma gerçekleştirmeyi zorlaştıran başlıca pratik nedenler arasında, araştırma için gereken özellik ve sayıda gönüllü danışan ve/veya psikolojik danışmanın bulunamaması (Cook ve Rumrill, 2005; Heppner ve diğ., 2008; Kazdin, 1978), mali sinırllıklar (Cook ve Rumrill, 2005; Heller, 1971; Heppner ve diğ., 2008) ve zaman açısından sinırlılıklar (Cook ve Rumrill, 2005) sayılabilir. Bunların yanı sıra, doğal psikolojik danışma koşullarında deneysel araştırma gerçekleştirirken, danışanları seçkisiz biçimde plasebo veya kontrol grubuna atamak gibi bazı deneysel işlemler ise etik sorunlara yol açabilecek başlıca etkenlerdendir (Cook ve Rumrill, 2005; Heppner ve diğ., 2008; Kazdin, 1978). Ayrıca Weidmann ve diğ. (2009), travmatik olaylarla ilgili deneysel araştırma gerçekleştiren araştırmacıların da etik nedenlerle sıklıkla analog araştırma yöntemine başvurduklarını belirtmektedir. Ancak analog araştırmaların en belirgin avantajı; araştırmacılara, deney koşullarını ve değişkenleri çok geniş bir biçimde kontrol etme olanağı sağlamasıdır (Gelso, 1979; Kazdin, 1978). Böylece, özellikle deneysel kontrol ve etik konularında sağladığı avantajlar sayesinde analog araştırmalar, çok spesifik meselelerin bile rahatlıkla incelenmesini mümkün kilar. Örneğin denekler, bir müdahale yönteminin spesifik unsurlarına veya müdahale yönteminin bütününe kolaylıkla maruz bırakılabilir veya bunlardan mahrum edilebilir ve deney kapsamında çeşitli gruplar (karşılaştırma grubu, plasebo grubu, kontrol grubu) kullanılabilir (Kazdin, 
1978). Bu özgürlük, analog araştırma yönteminin araştırmacılara sağladığı belki de en büyük avantajdır (Kazdin, 1978).

Analog araştırma yönteminin dezavantajlarıyla ilgili yapılan tartışmaların ise özellikle bir noktada, dış geçerlilik (genellenebilirlik) konusunda, yoğunlaştığı görülmektedir. Birçok araştırmacı, analog araştırmaların en belirgin ve önemli sınırlılı̆̆ının dış geçerlilik olduğunu ifade etmektedir (Cook ve Rumrill, 2005; Gelso, 1979; Heller, 1971; Heppner ve diğ., 2008; Hill, 1991; Kazdin, 1978; Meltzoff, 1979; Munley, 1974). Genel olarak, iç geçerliliği artırılmaya ağırlık verilen bir deneyde, dış geçerlilik azalma eğilimi gösterir (Kazdin ve Rogers, 1978). Bu nedenle, analog araştırmaların bulgularından yola çıkarak genelleme yaparken özellikle ihtiyatlı olunması önerilmektedir (Cowen, 1961; Meltzoff, 1979).

\section{Analog Araştırmalara İlişkin Kavramlaştırma ve Ölçütler}

Esasen analog araştırmalarla ilgili tartışmalar büyük ölçüde, deneysel psikolojik danışma araştırmalarının literatürde genellikle, analog araştırmalar ve doğal koşullarda gerçekleştirilen araştırmalar şeklinde ikiye ayrılarak kavramlaştırılmasından kaynaklanmaktadır (Kazdin, 1978). Kazdin (1978), deneysel araştırma yönteminin doğası gereği neredeyse tüm psikolojik deneylerin aslında birer analog araştırma olduğunu ve bu nedenle söz konusu kavramlaştırmanın, araştırmaların bulgularının doğru yorumlanması açısından yararlı olmadığını ileri sürmüştür. Literatürde, bir deneyin koşulları doğal koşullara ne kadar çok benzerse, deneyin bulgularının söz konusu doğal koşullara genellenebilirliğinin de o kadar artacağı farz edilmektedir (Kazdin, 1978). Bu doğrultuda Kazdin'e göre, bir deneysel psikolojik danışma araştırması değerlendirilirken göz önünde bulundurulması gereken esas mesele; deney koşullarının her birinin [ör. psikolojik danışmanların, danışanların, psikolojik danışma sürecinin (deneysel müdahalenin), psikolojik danışma sürecinin yürütüldüğü ortamın, değerlendirme işlemlerinin], araştırmacının genellemede bulunmak istediği koşullara ne kadar benzediğidir.

Bordin (1965) ise analog araştırmaları daha geniş bir açıdan ele almış ve aslında yapılan işin, bir araştırma yöntemi olarak sadeleştirme olduğunu ifade etmiştir. Bordin sadeleştirmeyi, neredeyse hiçbir değişikliğin yapılmadığı doğal koşullar ile araştırmacı tarafından olabildiğince çok değişiklik ve soyutlamanın yapıldığı laboratuvar koşulları arasında uzanan bir süreklilik olarak düşünmüş ve böylece, doğal koşullar ile laboratuvar koşulları arasındaki ikiliğin, karşıtlığın esasen anlamsız olduğunu belirtmiştir. Bordin'e göre sadeleştirme, bilgi elde etme sürecinin gerekli bir parçasıdır, fakat iyi ve kötü yapılan sadeleştirmeler 
bulunmaktadır. Bu yönde Bordin, yapılacak sadeleştirmenin kabul edilebilir olması için dikkate alınması gerektiğini ileri sürdüğü üç kural sunmuştur:

1. Merakımızı uyandıran ve hakkında daha fazla şey öğrenmek veya hakkındaki düşüncelerimizi doğrulamak istediğimiz doğal fenomenden yola çıkmalı ve o doğal koşulları odak noktasinda tutmalıyı.

2. Doğal koşullardan güvenli bir biçimde uzaklaşabileceğimiz mesafe; söz konusu fenomen hakkında hâlihazırda sahip olduğumuz bilginin miktarıyla, buna ne kadar izin verdiğiyle orantilidir.

3. Eğer sadeleştirme mevcut bilgimize dayanmıyorsa; sadeleştirme ile amaçlanan doğal fenomen arasında köprü kuracak, arasındaki boşlukları dolduracak araştırmaları bir an önce gerçekleştirerek sadeleştirmeyi doğrulamalıyız.

Son olarak, Strong (1971) da analog araştırmaların bulgularının psikolojik danışmada uygulamaya geçirilirken göz önünde bulundurulmasının gerekli olduğunu belirttiği, psikolojik danışmaya dair beş sınır koşulu sunmuştur. Strong'a göre, psikolojik danışmanın bu beş sınır koşulunu karşılayan analog araştırmaların bulguları, psikolojik danışmada doğrudan uygulamaya geçirilebilecektir:

1. Psikolojik danışma, kişiler arasında geçen bir karşılıklı konuşmadır. $\mathrm{Bu}$ nedenle davranış değişimi, kişiler arası etkileşimle sağlanmalıdır.

2. Etkileşimde bulunan kişiler arasındaki statü farklılığ karşıllıklı konuşmayı kısıtlar. Psikolojik danışman yardım veren; danışan, yardım alan kişidir. Karşılıklı konuşma simetrik değildir, çünkü katılımcıların katkıları eşit değildir.

3. Psikolojik danışmada etkileşimde bulunan kişiler arasındaki ilişkinin süresi değişiklik gösterir ve bazen zamana yayılır. Bu süre, etkileşimdeki diğer faktörlerin etkilerini azaltabilir. Laboratuvar koşullarında gerçekleştirilen deneylerin çoğu, bir veya en iyi ihtimalle birkaç oturum sürer.

4. Birçok danışan, değişim için motive olmuştur. Psikolojik danışma almak için aktif olarak uğraşır, bazı değişimleri gerçekleştirmek ister ve psikolojik danışma süreç ve sonucuna kişisel olarak dâhil olurlar. Danışanlar etkilenmeye hazır olduğu hâlde, laboratuvar koşullarında gerçekleştirilen deneylerdeki denekler hazır değildir. 
5. Birçok danışan psikolojik olarak sıkıntı çekmekte ve davranışlarını değiştirmek için yoğun bir çaba harcamaktadır.

\section{Tartışma ve Sonuç}

Deneyler, sorunları daha iyi anlamamızı sağlarlar (Lazarus, 1963). Gelso (1979), deneysel araştırma gerçekleştirmenin, bir otomobilin ön camına yapışkan etiket yapıştırmaya benzediğini ifade etmiştir; yapıştırma sırasında etiketin altında bir hava kabarcığı ortaya çıkar ve otomobilin sahibi, yok etmek için hava kabarcığının üstüne her bastırdığında, hava kabarcı̆̆ı başka bir yerde tekrar ortaya çıkar. Gelso'ya göre, sözünü ettiği bu hava kabarcığı hipotezi, bütün deneylerin aslında son derece kusurlu olduğunu vurgulamaktadır. Bunun yanında, analog araştırmaların en belirgin ve önemli sınırlılığı olduğu belirtilen, araştırmaların bulgularının dış geçerliliği meselesi de aslında bütün deneysel araştırmalar için ortak bir meseledir (Heller, 1971; Kazdin ve Rogers, 1978). Bu koşullar altında, bir analog araştırma gerçekleştirilmesi söz konusu olduğunda yapılması gereken, iç ve dış geçerliliğ̈in dengelenmeye çalışıldığı bir araştırma gerçekleştirmektir; böylece, elde edilen bulgular daha güçlü olacaktır (Heppner ve diğ., 2008).

Sonuç olarak analog araştırmalar, psikolojik danışmaya (psikolojik danışma süreci, sonucu, eğitimi ve süpervizyonuna) ilişkin araştırmaların ilerlemesi için oldukça gereklidir (Scheel ve diğ., 2011b) ve analog araştırma yönteminin etkili, yararlı ve tavsiye edilmeye değer olduğu şüphesizdir (Goldstein ve diğ., 1966; Heppner ve diğg., 2008). Birçok araştırmacı analog araştırma yönteminin özellikle, tamamen doğal psikolojik danışma koşullarında gerçekleştirilecek araştırmalardan önce, bir ön inceleme olarak kullanılmasını önermektedir (Cook ve Rumrill, 2005; Meltzoff, 1979; Scheel ve diğ., 2011a). Türkiye'de de psikolojik danışma alanında deneysel araştırma yöntemiyle ele alınması gereken (ör. kültüre özgü ve daha etkili müdahale yöntemlerinin geliştirilmesi konusunda) çok fazla temel mesele bulunmaktadır ve bu konuda araştırmacılara yardımcı olabilecek başta gelen yöntemlerden biri, Bordin'in (1965) ifadesiyle sadeleştirme, yani analog araştırmalardır.

Bunların yanı sıra, Türkiye'de psikolojik danışma araştırmaları alanında, yöntem bilimsel ciddi bir tartışmanın veya yöntem arayışının bugüne kadar kendine neredeyse hiç yer bulamadığı görülmektedir. Oysa yöntem bilimsel tartışmaların, incelemelerin yapılmadığı bir alanda, araştırmaların nitelik ve uygulamaya ilişkin değerinin anlamlı düzeyde artması pek mümkün değildir. Ayrıca, Türkiye dışında yapılan yöntem bilimsel tartışmaların, Türkiye'deki araştırmaların niteliğinin artmasına katkısı; kültürel, dilsel, tarihsel vb. nedenlerle doğal olarak sınırlı olmaktadır. Eğer Türkiye'de psikolojik danışma 
araştırmaları alanında, araştırmaların nitelik ve uygulamaya ilişkin değeri açısından anlamlı düzeyde bir gelişme sağlanmak isteniyorsa, bu makalede biraz da olsa gerçekleştirilmeye çalışılan yöntem bilimsel tartışmanın, incelemenin (ör. Bordin, 1965; Gelso, 1979; Kazdin, 1978; Strong; 1971) Türkiye' de daha fazla yapılması gereklidir. 
Kaynakça

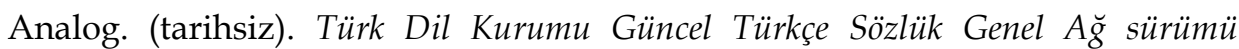
içinde.

http://www.tdk.org.tr/index.php?option=com_gts\&arama=gts\&guid=T DK.GTS.51f670a092c529.72127182 adresinden elde edildi.

Bordin, E.S. (1965). Simplification as a strategy for research in psychotherapy. Journal of Consulting Psychology, 29, 493-503. doi:10.1037/h0022760

Borkovec, T. ve Rachman, S. (1979). The utility of analogue research. Behaviour Research and Therapy, 17, 253-261. doi:10.1016/0005-7967(79)90040-8

Cook, B. G. ve Rumrill, P. D. (2005). Using and interpreting analogue designs. Work: A Journal of Prevention, Assessment and Rehabilitation, 24(1), 93-97.

Cowen, E. L. (1961). The experimental analogue: An approach to research in psychotherapy. Psychological Reports, 8, 9-10. doi:10.2466/pr0.1961.8.1.9

Erford, B. T., Miller, E. M., Schein, H., McDonald, A., Ludwig, L. ve Leishear, K. (2011). Journal of counseling \& development publication patterns: Author and article characteristics from 1994 to 2009. Journal of Counseling E Development, 89, 73-80. doi:10.1002/j.1556-6678.2011.tb00062.x

Gelso, C. J. (1979). Research in counseling: Methodological and professional $\begin{array}{lllll}\text { issues. The Counseling Psychologist, } & \text { 8, }\end{array}$ doi:10.1177/001100007900800303

Goldstein, A. P., Heller, K. ve Sechrest, L. B. (1966). Psychotherapy and the psychology of behavior change. New York, NY: John Wiley and Sons.

Güven, M., Kısaç, İ., Ercan, L. ve Yalçın, İ. (2009). Türk psikolojik danışma ve rehberlik dergisinde yayınlanan makalelerin çeşitli özellikler açısından incelenmesi. Türk Psikolojik Danışma ve Rehberlik Dergisi, 4(31), 80-87.

Harmon, L. W. (1978). The counselor as consumer of research. İçinde L. Goldman (Ed.), Research methods for counselors: Practical approaches in field settings. (s. 29-78). New York, NY: John Wiley and Sons.

Heller, K. (1971). Laboratory interview research as analogue to treatment. İçinde A. E. Bergin ve S.L. Garfield (Ed.), Handbook of psychotherapy and behavior change: An empirical analysis. (s. 126-153). New York, NY: John Wiley and Sons.

Heppner, P. P., Wampold, B. E. ve Kivlighan, D. M., Jr. (2008). Research design in counseling (3. Baskı). Belmont, CA: Thomson Brooks/Cole.

Hill, C. E. (1991). Almost everything you ever wanted to know about how to do process research on counseling and psychotherapy but didn't know who to ask. C. E. Watkins, Jr. \& L. J. Schneider (Eds.), Research in counseling (s. 85-118) içinde. Hillsdale, NJ: Lawrence Erlbaum. 
Kazdin, A. E. (1978). Evaluating the generality of findings in analogue therapy research. Journal of Consulting and Clinical Psychology, 46, 673-686. doi:10.1037/0022-006X.46.4.673

Kazdin, A. E. (1991). Research design in clinical psychology (2. Baskı). Boston, MA: Allyn and Bacon.

Kazdin, A. E. ve Rogers, T. (1978). On paradigms and recycled ideologies: Analogue research revisited. Cognitive Therapy and Research, 2, 105-117. doi:10.1007-bf01172519

Keet, C. D. (1948). Two verbal techniques in a miniature counseling situation. Psychological Monographs: General and Applied, 62(7, Whole No. 294), i-56. doi:10.1037/h0093586

Kiesler, D. J. (1971). Experimental designs in psychotherapy research. İçinde A.E. Bergin ve S.L. Garfield (Ed.), Handbook of psychotherapy and behavior change: An empirical analysis. (s. 36-74). New York, NY: John Wiley and Sons.

Kushner, K. (1978). On the external validity of two psychotherapy analogues. Journal of Consulting and Clinical Psychology, 46, 1394-1402. doi:10.1037/0022-006X.46.6.1394

Lazarus, R. S. (1963). A laboratory approach to the dynamics of psychological stress. Administrative Science Quarterly, 8(2), 192-213.

Meltzoff, J. (1979). Commentary and reflections on research in counseling. The Counseling Psychologist, 8, 36-39. doi:10.1177/001100007900800304

Munley, P. H. (1974). A review of counseling analogue research methods. Journal of Counseling Psychology, 21, 320-330. doi:10.1037/h0036734

Scheel, M. J., Berman, M., Friedlander, M. L., Conoley, C. W., Duan, C. ve Whiston, S. C. (2011a). Whatever happened to counseling in counseling psychology? The Counseling Psychologist, 39, 673-692. doi:10.1177/0011000010380278

Scheel, M. J., Berman, M., Friedlander, M. L., Conoley, C. W., Duan, C. ve Whiston, S. C. (2011b). Counseling-related research in counseling psychology: Creating bricks, not edifices. The Counseling Psychologist, 39, 719-734. doi:10.1177/0011000011410894

Strong, S. R. (1971). Experimental laboratory research in counseling. Journal of Counseling Psychology, 18, 106-110. doi:10.1037/h0030614

Weidmann, A., Conradi, A., Gröger, K., Fehm, L. ve Fydrich, T. (2009). Using stressful films to analyze risk factors for PTSD in analogue experimental studies - which film works best? Anxiety, Stress, \& Coping, 22(5), 549-569. doi:10.1080/10615800802541986 
Zane, N., Hall, G. C. N., Sue, S., Young, K. ve Nunez, J. (2004). Research on psychotherapy with culturally diverse populations. M. J. Lambert (Ed.), Bergin and Garfield's handbook of psychotherapy and behavior change (5. Baskı) (s. 767-804) içinde. New York, NY: Wiley. 